\title{
Formação docente e pandemia do COVID-19: limites e possibilidades na perspectiva graduandos do ICED-UFPA
}

Teacher training and the COVID-19 pandemic: limits and possibilities from the perspective of ICEDUFPA undergraduates

La formación docente y la pandemia COVID-19: límites y posibilidades desde la perspectiva de los estudiantes de grado ICED-UFPA

Recebido: 24/08/2021 | Revisado: 29/08/2021 | Aceito: 14/09/2021 | Publicado: 15/09/2021

\author{
Maria José de Castro Nunes \\ ORCID: https://orcid.org/0000-0002-3409-9227 \\ Universidade Federal do Pará, Brasil \\ E-mail:maria.nunes@iced.ufpa.br \\ Antônio Cláudio Andrade dos Reis \\ ORCID: https://orcid.org/0000-0003-1305-9469 \\ Universidade Federal do Pará, Brasil \\ E-mail:aclaudioreis@yahoo.com.br \\ Marcelo Wilson Ferreira Pacheco \\ ORCID https://orcid.org/0000-0001-5681-9670 \\ Universidade Federal do Pará, Brasil \\ E-mail: celopacheco@hotmail.com \\ Willian Lazaretti da Conceição \\ ORCID https://orcid.org/0000-0001-8143-6524 \\ Universidade Federal do Pará, Brasil \\ Universidade Nova de Lisboa, Portugal \\ E-mail:lazaretti@ufpa.br
}

\begin{abstract}
Resumo
O presente artigo tem por objetivo apresentar uma análise das condições objetivas na efetividade do Ensino Remoto e os impactos causados na vida de estudantes no contexto situado dos cursos de graduação do Instituto de Ciências da Educação (ICED), da Universidade Federal do Pará (UFPA), destacando os limites e possibilidades no acesso e permanência de acadêmicos/as ao Ensino Remoto na perspectiva da escuta sensível da voz discente, sobre o acesso e uso de recursos tecnológicos e digitais no cenário atual com a pandemia ocasionada pelo COVID-19. Optou-se por uma pesquisa exploratória do tipo mista, utilizando como instrumento de coleta de dados questionário pela plataforma Google Forms, tendo como público-alvo os/as discentes matriculados/as nos cursos de Pedagogia e Educação Física, evidenciando dados predominantemente qualitativos que foram tratados com a técnica de análise temática. Os principais resultados apresentam dados reveladores quanto a: a) Condições materiais de acesso às tecnologias digitais, uso dos equipamentos tecnológicos e atividades online e offline; b) Percepção dos estudantes sobre a Educação no Ensino Remoto no período da pandemia e c) Conflitos subjacentes ao Ensino Remoto durante a pandemia.
\end{abstract}

Palavras-chave: COVID-19; Pandemia; Ensino remoto.

\begin{abstract}
This article aims to present an analysis of the objective conditions in the effectiveness of Remote Teaching and the impacts caused on the lives of students in the context of undergraduate courses at the Institute of Educational Sciences (ICED), Federal University of Pará (UFPA), highlighting the limits and possibilities in the access and permanence of students to Remote Education from the perspective of sensitive listening to the student voice, on the access and use of technological and digital resources in the current scenario with the pandemic caused by COVID-19. We opted for exploratory research of the mixed type, using a questionnaire by the Google Forms platform as a data collection instrument, with the target audience of students enrolled in Pedagogy and Physical Education courses, showing predominantly qualitative data that were treated with the technique of thematic analysis. The main results present revealing data regarding: a) Material conditions of access to digital technologies, use of technological equipment and online and offline activities; b) Students' perception of Education in Remote Learning during the pandemic period and c) Conflicts underlying Remote Learning during the pandemic.
\end{abstract}

Keywords: COVID-19; Pandemic; Remote teaching. 


\begin{abstract}
Resumen
Este artículo tiene como objetivo presentar un análisis de las condiciones objetivas en la efectividad de la Enseñanza Remota y los impactos causados en la vida de los estudiantes en el contexto de los cursos de pregrado en el Instituto de Ciencias de la Educación (ICED), Universidad Federal de Pará (UFPA), destacando los límites y posibilidades en el acceso y permanencia de los estudiantes a la Educación Remota desde la perspectiva de la escucha sensible de la voz del estudiante, sobre el acceso y uso de los recursos tecnológicos y digitales en el escenario actual con la pandemia provocada por COVID-19. Se optó por una investigación exploratoria de tipo mixto, utilizando un cuestionario de la plataforma Google Forms como instrumento de recolección de datos, con el público objetivo de estudiantes matriculados en cursos de Pedagogía y Educación Física, mostrando datos predominantemente cualitativos que fueron tratados con la técnica de Análisis temático. Los principales resultados presentan datos reveladores sobre: a) Condiciones materiales de acceso a tecnologías digitales, uso de equipos tecnológicos y actividades online y offline; b) Percepción de los estudiantes sobre la Educación Remota durante el período pandémico yc) Conflictos subyacentes al Aprendizaje Remoto durante la pandemia.
\end{abstract}

Keywords: COVID-19; Pandemia; Enseñanza remota.

\title{
1. Introdução
}

A crise sanitária mundial surgida na província de Wuhan, na China, no início de dezembro de 2019, e que rapidamente se proliferou em todo o mundo, ocasionou mudanças na vida da população em todos os sentidos. Em 11 de março de 2020 , oficialmente a Organização Mundial da Saúde (OMS), declara que estamos vivendo uma pandemia do Novo Coronavírus (COVID-19), denominado de SARS-COV 2. Pandemia é um termo usado quando uma doença se espalha de maneira contínua e simultânea em vários continentes - o coronavírus é causado por um vírus altamente contagioso, transmitido por via respiratória, através do contato pessoal próximo, por isso a necessidade de isolamento social.

Seguindo as orientações estabelecidas pela OMS, no Brasil, medidas de isolamento social ou quarentena foram declaradas, tais ações essas que demandam medidas urgentes de prevenção e controle da disseminação do vírus. Assim, novas maneiras tiveram de ser adequadas às rotinas em todos os âmbitos, inclusive no educacional, os reflexos foram percebidos de forma imediata devido à necessidade do isolamento social, com a suspensão das aulas presenciais (Brasil, 2020)

Com o avanço da pandemia e as condições sanitárias inadequadas para o retorno das atividades presenciais, medidas emergenciais tiveram de ser desenvolvidas no intuito de dar continuidade aos processos educativos. No entanto as definições das medidas para o prosseguimento das atividades educacionais não dispunham do preparo necessário para gerir a crise instaurada pelo novo coronavírus, tal fato apresentou-se como uma perspectiva importante no contexto da inserção de um novo modelo de ensino baseado nas ações tecnológicas e do ensino remoto. O impacto causado por um vírus infeccioso e letal provocou mudanças em nosso cotidiano e nos fez repensar novas práticas no ensino e aprendizagem, tendo sido necessário se reinventar como cidadãos, profissionais e estudantes, além de também servir para acentuar as desigualdades sociais no acesso à educação de qualidade e às mídias digitais.

A nova realidade da Educação brasileira, assim deixa transparecer essas dificuldades que por anos passaram despercebidas aos olhos da maioria dos envolvidos na área. A Carta Cidadã, no artigo 205, estabelece que a educação é um direito de todos e dever do Estado e da família, será promovida e incentivada com a colaboração da sociedade, visando ao pleno desenvolvimento da pessoa, seu preparo para o exercício da cidadania e sua qualificação para o trabalho (Brasil, 1988). Mas essa democratização do ensino no Brasil ainda se trata de um sonho distante. O artigo 26 da Lei do Marco Civil da Internet cita a Educação como dever do Estado, de modo a incluir nas práticas educacionais o uso seguro, consciente e responsável da internet como ferramenta para o exercício da cidadania, a promoção da cultura e o desenvolvimento tecnológico (Brasil, 2014).

Diante desse cenário, a Universidade Federal do Pará, por meio do seu Conselho Superior de Ensino, Pesquisa e Extensão (CONSEPE), aprovou, de forma excepcional e temporária, o Ensino Remoto Emergencial - ERE, que dentre algumas finalidades, destacam-se: 
I. Realização de atividades por meios digitais (salas de webconferência; vídeoaulas exibidas ao vivo ou gravadas; conteúdos em diferentes linguagens e formatos organizados em ambientes virtuais de ensino e aprendizagem; correio eletrônico; sites de redes sociais; aplicativos de mensagens instantâneas, entre outros); II. Adoção de técnicas e estratégias e de materiais didáticos com orientações pedagógicas divulgados por meio de canais acessíveis aos(às) estudantes; II. Estabelecimento, por meios digitais, de canal de contato direto entre estudantes e docentes responsáveis, para organização de atividades de Ensino Remoto Emergencial (ERE) e garante no Art. $2^{\circ}$. A adoção do Ensino Remoto Emergencial (ERE) deverá ser acompanhada de Programas de Inclusão Digital voltados aos(às) discentes em condição de vulnerabilidade socioeconômica, observadas as demandas e especificidades das Unidades Acadêmicas (Universidade Federal do Pará, 2020).

Assim, instigados pelas conversas e inquietações com os colegas, sobre as dificuldades contrastadas durante o Ensino Remoto, sentimos a necessidade de conhecer e compreender as realidades encaradas por eles e como se deu a sua participação nas atividades online e offline ofertadas pela Universidade, considerando as realidades e peculiaridades de cada um, sobretudo com relação aos recursos estrutura que cada um dispunha. Vale destacar que, durante esse período de isolamento social, muitos saíram da Capital onde estudam e partiram para junto de seus familiares em Comunidades, Quilombos, Região das Ilhas e demais municípios do Estado.

Mediante a todo esse contexto e relevância do tema em questão, o presente trabalho tem como objetivo geral analisar as condições objetivas para a efetividade no Ensino Remoto (ER) e seu impacto na vida de estudantes dos cursos de graduação do Instituto de Ciências da Educação (ICED), da Universidade Federal do Pará (UFPA), destacando limites e possibilidades no acesso e permanência de acadêmicos/as no Ensino Remoto e como objetivos específicos destacam-se; identificar as estratégias de ensino, os recursos pedagógicos e tecnológicos, o processo de avaliação da aprendizagem; analisar os impactos causados pela pandemia na formação do/a professor/a. O método utilizado nesta pesquisa mista tem abordagem exploratória, qualitativa e análise temática, consiste em revisão bibliográfica e elaboração de questionário online, respondidos via google forms, mesclandose perguntas fechadas e abertas. Utilizou-se como veículo de comunicação com os alunos e recebimento dos questionários, o whatsapp $e$ teve como público-alvo os estudantes de graduação dos cursos de Pedagogia e Educação Física, do Instituto de Ciências da Educação, da Universidade Federal do Pará.

\section{Referencial Teórico}

\subsection{Desigualdades na educação: condições de acesso e qualidade da oferta}

Diante da crise instalada pela pandemia e seus impulsos causados na educação brasileira, a fim de evitar as aglomerações e prevenir o contágio e consequentemente o avanço do vírus, as instituições de ensino tiveram como imediata ação criar estratégias rígidas que visam o isolamento social, ocasionando assim a suspensão das aulas presenciais e demais atividades voltadas à formação discente.

A alternativa encontrada para minimizar esses impactos ocasionados pela pandemia do COVID-19 foram as aulas online, ensino à distância e/ou ensino remoto, assim denominadas em substituição às aulas presenciais. Todos esses transtornos que mundialmente estão nos afetando nos faz refletir que essa crise é planetária e mostra que nós, indivíduos, e a comunidade somos indissociáveis. Somos pequenos demais (Silva, 2020).

Além dos problemas relacionados à saúde e economia, diante de tantas incertezas quanto ao futuro, outro fator que ficou evidenciado foram as desigualdades de acesso ao direito à educação, estabelecido no artigo 205 da Constituição Federal como sendo a educação, um direito de todos e dever do Estado e da família (Brasil, 1988), tendo como finalidade segundo a Lei de Diretrizes e Bases da Educação - LDB o pleno desenvolvimento do educando, seu preparo para o exercício da cidadania e sua qualificação para o trabalho (Brasil, 1996). Assim sendo, a continuação das aulas por meio de ensino remoto de aprendizagem, que primam pelas metodologias usadas na Educação a Distância, feitas através de smartphones e/ou computador, firmam o compromisso, ainda que a curto prazo, de manter o processo educativo. 
Diante da imprevisibilidade da duração da pandemia e das dificuldades ao seu acesso:

Os impactos intertemporais da pandemia da COVID-19 sobre a educação são preocupantes pois reproduzem de modo ampliado assimetrias previamente existentes nas sociedades, de modo que os atores econômicos privilegiados e com amplo acesso ao ensino privado e às Tecnologias de Informação e Comunicação (TICs) conseguem minimizar os efeitos pandêmicos no curto prazo por meio da continuidade educacional via EAD em contraposição a atores econômicos mais vulneráveis (Senhoras, 2020, p. 134).

Em meio a tudo o que chegou junto com o COVID-19, veio também a necessidade de tomar decisões e ações no âmbito educacional, da noite para o dia, a fim de dar seguimento às formações em andamento, o Conselho Nacional de Educação (CNE), posicionou-se dizendo que as atividades pedagógicas não presenciais serão computadas para fins de cumprimento da carga horária mínima anual destacando que essas atividades podem ser desenvolvidas por meios digitais (Parecer CNE/CP n ${ }^{\circ}: 5,2020$ ).

É nesse contexto que surge uma nova configuração para os processos de ensino e de aprendizagem, denominado de Ensino Remoto, isto é, onde se faz uso de práticas pedagógicas mediadas por plataformas digitais, como aplicativos com os conteúdos, tarefas, notificações e/ou plataformas síncronas e assíncronas como o Google Classroom, Google Meet, Google Drive, Whatsapp, dentre outras. Tais práticas do ensino remoto vêm crescendo no mundo todo por conta da pandemia e se caracterizam com encontros frequentes durante a semana, seguindo o cronograma das atividades presenciais realizadas antes do distanciamento imposto pela grave crise sanitária.

O ambiente da sala de aula, com suas paredes e alunos/as postos em cadeiras, já não pode ser entendida apenas como espaço físico, esse "novo ambiente" foi substituído por uma tela fria de smartphone e/ou computador, onde apenas se pode ver o/a aluno/a através de uma simples foto ou imagem aleatória, esse encontro entre professor/a e a sala de aula e o horário das aulas presenciais medidas, provisoriamente, não nos pertencem mais. É tempo de (re)significar as práticas e deixar emergir o Talento Artístico de cada um (Almeida et al., 2020). E, na prática, esse cenário tem causado inquietação de professores/as e alunos/as, que tentam dar continuidade ao ensino, mediados pelas Tecnologias Digitais da Informação e Comunicação (TDICs), mais precisamente, as tecnologias digitais anteriormente mencionadas.

Essas mudanças nos levam a reflexões acerca dos novos rumos no processo de ensino e de aprendizagem, impostos pelo ensino remoto e o uso das tecnologias digitais como reinvenção das práticas pedagógicas que o atual contexto exige. Muitos são os desafios e articulações mediante o uso da tecnologia às práticas pedagógicas no cotidiano. Essa perspectiva de repensar essas concepções, idealizadas como práxis, que é um instrumento de mudança da ação docente, ou seja, como uma conduta consciente e participativa, que surge da multidimensionalidade que cerca o ato educativo (Franco, 2016), organizada em meio a intencionalidades, cujas práticas (re)construídas dão sentido a tais intencionalidades.

Acerca de uma metáfora que relata sobre as emoções desencadeadas pelo virtual no ser humano:

Seres humanos, pessoas daqui e de toda parte, vocês que são arrastados no grande movimento da desterritorialização, [...] vocês que pensam reunidos e dispersos entre o hipercórtex das nações, vocês que vivem capturados, esquartejados, nesse imenso acontecimento do mundo que não cessa de voltar a si e de recriar-se, vocês que são jogados vivos no virtual, vocês que são pegos nesse enorme salto que nossa espécie efetua em direção à nascente do fluxo do ser, sim, no núcleo mesmo desse estranho turbilhão, vocês estão em sua casa. Bem-vindos à nova morada do gênero humano. Bemvindos aos caminhos do virtual (Lévy, 1999 apud Oliveira et al., 2020, p. 28).

Professores/as e alunos/as foram "jogados vivos no virtual" e subitamente se viram obrigados a lidar com essa nova configuração de ensino e aprendizagem. Mas, na atualidade, é incontestável que possamos saber enfrentar os desafios e encontrar as saídas para dar continuidade às atividades, mas tem sido possível se reinventar e aprender. Ninguém estava realmente preparado para essa provocação. Almeida et al. (2020) afirmam que em toda crise também é, ou tem grande potencial para ser uma oportunidade. 
Uma crise, para além da desestabilização e da incerteza que acarreta, se manifesta pela insuficiência das regulações de um sistema que, para manter sua estabilidade, inibe ou repele os desvios (feedback negativo). Deixando de ser repelidos, os desvios (feedback positivo) transformam-se em tendências ativas que, se desenvolvidas, ameaçam cada vez mais desregular e bloquear o sistema em crise. Nos sistemas vivos, sobretudo os sociais, o desenvolvimento vitorioso dos desvios convertidos em tendências conduz às transformações, regressivas ou progressivas, ou mesmo a uma revolução (Almeida et al., 2020, p. 30).

Outro tema que tem sido discutido de modo veemente tem relação com as assimetrias sociais e econômicas, que tornaram-se cada vez mais evidentes nesse período de pandemia. O acesso à educação "isolou" alguns, acentuando as desigualdades sociais e negando ainda mais o direito estabelecido na Constituição Federal (C.F) e a Lei de Diretrizes e Bases da Educação que preconizam a educação como direito e reforçam o princípio da igualdade de condições para o acesso e permanência na escola (Brasil, 1988; Brasil, 1996; Silva et al. 2021; Conceição et al., 2021).

Segundo dados do Instituto Brasileiro de Geografia e Estatística (IBGE, 2019) dentre uma das dificuldades para o acesso à educação de qualidade está relacionada ao acesso à internet. Conforme dados da pesquisa realizada pela Pesquisa Nacional por Amostras de Domicílios Contínua - PNAD, no Brasil 86,7\% dos domicílios têm acesso à internet, sendo que na região Norte esse percentual atinge 76\%. Em 2019, em 12,6 milhões de domicílios do País não havia utilização da Internet, o que representava, em conjunto, $84,8 \%$. Esses três motivos foram relatados para justificar a não utilização da internet: falta de interesse em acessar a Internet (32,9\%), serviço de acesso à Internet era caro $(26,2 \%)$ e nenhum morador sabia usar a Internet $(25,7 \%)$. Outrossim, o motivo de o serviço de acesso à Internet não estar disponível na área do domicílio abrangeu 6,8\% das residências em que não havia utilização da Internet e o motivo de o equipamento eletrônico para acessar a Internet ser caro, 5,0\%. Dentre os equipamentos mais utilizados para acessar a Internet no domicílio, o uso do telefone móvel celular continuou à frente e já próximo de alcançar a totalidade dos domicílios que acessam a Internet (99,5\%). Em segundo lugar, bem abaixo da metade dos domicílios em que havia acesso à Internet, estava o microcomputador (45,1\%), seguido pelo tablet (12,0\%).

Em 2019, na população de 183,3 milhões de pessoas, na faixa etária de 10 anos ou mais de idade do País, 78,3\% (ou 143,5 milhões) utilizaram a Internet no período de referência dos últimos três meses. Sendo que os resultados desse percentual de pessoas que acessaram a Internet da Região Norte (69,2\%), permanecendo inferior aos alcançados nas demais regiões do Brasil, somando-se a isso que, mesmo com acesso à internet, em muitos casos, a conexão é de baixíssima qualidade (IBGE, 2019; Stringhini et al., 2021).

\subsection{O ensino remoto em tempos de pandemia do Coronavírus}

O início das atividades remotas, embora tenha sido de maneira repentina e assustadora, trouxe profundas mudanças nas concepções e hábitos estabelecidos pela educação tradicional. Foi necessário colocar em evidência a relevância das características que o ensino remoto requer, quais sejam: disciplina, autonomia, acesso a dispositivos de Tecnologia Digital da Informação e Comunicação (TDIC), sobretudo a internet, assim como adoção de espaço apropriado para estudos, dentre outros fatores. Com essas novas alternativas, o redesenhar e repensar diante de uma nova realidade inesperada trouxe sacrifícios e, consequentemente, muitas mudanças na forma de pensar, mas não deixando de enfatizar que a educação remota não é a solução para os problemas acarretados à educação pela pandemia, é a política de redução de danos e tem que ser considerada e realizada, considerando que o uso das tecnologias digitais não substituem o papel do professor e as vivências dentro do espaço educacional, porém, é um recurso de viabilizar acesso e possibilidades de desenvolvimento de novas práticas educativas (Almeida et al. 2020; Costa \& Conceição, 2021a, 2021b).

Um alerta sobre o uso da tecnologia como um mero recurso didático, não contribuindo para as práticas colaborativas no processo de ensinar e aprender:

A tecnologia pode ser compreendida como meros recursos didáticos, utilizadas como meio para atingir um determinado 
objetivo, como repositórios de textos, para animar e tornar as "aulas" mais interessantes e se aproximar do universo digital dos seus estudantes. Tal perspectiva pode ser útil, mas não contribui para aprendizagem e práticas colaborativas entre os sujeitos do processo de ensinar e aprender (Alves, 2020, p. 358).

Na educação remota há o predomínio de uma adaptação temporária das mesmas metodologias utilizadas no regime presencial, as aulas são realizadas nos mesmos dias e horários, com os professores responsáveis pelas disciplinas dos cursos presenciais. Esses professores estão tendo que elaborar os materiais para realização das atividades, criando slides, vídeos, entre outros recursos para ajudar os alunos na compreensão e participação das atividades. Mas, nem sempre a qualidade destes materiais confeccionados atende aos objetivos desejados.

O papel do/a professor/a nesse contexto pandêmico é de uma grande responsabilidade social e política, visando o bemestar de seus alunos no processo educacional, como Oliveira et al. (2020) acentuam que os professores têm que atuar como permanentes aprendizes e aprender a se comunicar na linguagem e estilo de seus estudantes; exigindo deles o repensar seus modos de atuação, compreendendo as tecnologias digitais para assim integrá-las ao ensino, utilizando- as de forma crítica, reflexiva e significativa.

Sobre a importância em formar-se para (trans) formar:

Entende que, mais importante do que formar, é formar-se e que o aprender contínuo é essencial à profissão docente, sendo marcado pela própria pessoa do professor, como agente, entendendo a instituição escolar como um espaço de crescimento profissional permanente. Então, podemos dizer que as ações de formação docente, tendo como pano de fundo a integração das TD ao fazer pedagógico, precisam tomar a escola como principal locus de formação, em que os professores atuem em constante colaboração (Oliveira et al. 2020, p. 32).

Diante dessa perspectiva de formação, a função do/a professor/a torna-se cada vez mais complexa. Por isso, é necessário repensar a formação dos professores para que possam enfrentar as novas e diversificadas tarefas que lhes são confiadas na sala de aula e além dela (Diretrizes Curriculares Nacionais da Educação Básica, 2013).

\subsection{O uso das tecnologias digitais em tempos de pandemia}

O ensino por meio da Educação a Distância $(\mathrm{EaD})$ é uma possibilidade antiga e como muitos acreditam, não surgiu na presente época digital. No século XIX, já se utilizavam as correspondências para enviar guias de estudos de línguas às residências, que tinham como alvo atingir pessoas desfavorecidas socialmente, especialmente as mulheres. Na década de 1920, no Brasil já existiam os primeiros cursos que eram transmitidos através das ondas do rádio, uma novidade tecnológica da época. Seguindo pelas décadas de 1940 e 1950, teve o surgimento dos cursos profissionalizantes, liderados pelos Institutos Monitor, Universal Brasileiro e pela Universidade do Ar, patrocinados pelo Senac e pelo Sesc, sendo que até hoje algumas dessas instituições ainda permanecem voltadas à formação profissional através de cursos a distância.

Nos anos de 1960 e 1970 várias outras iniciativas de EaD surgiram a fim de ampliar o acesso à educação, promovendo o letramento e a inclusão social de adultos, através das Universidades Abertas, que ofereciam ensino de qualidade com custo reduzido às pessoas não universitárias. Com o passar do tempo, à medida que as tecnologias de comunicação foram evoluindo, as possibilidades de EaD também foram se ampliando.

No final da década de 1970 teve início em Brasília a primeira experiência de EaD nos cursos superiores. Nesse período, muitos já acompanhavam os telecursos, transmitidos via teleconferências por áudio, vídeo e computador, direcionado às pessoas que aprendem sozinhas, geralmente estudando em casa.

Nos anos 2000, as instituições passaram a utilizar a internet para publicar conteúdos e promover interações entre os alunos, que apresenta como forma de comunicação síncrona e/ou assíncrona, onde se há um contato em tempo real ou não, com o professor e com colegas de curso. 
Assim observa-se que essa evolução tecnológica da qual a $\mathrm{EaD}$ faz parte pode ser dividida em fases cronológicas e as diferentes tecnologias utilizadas para a viabilização da $\mathrm{EaD}$ foram os materiais impressos, rádio/televisão, e logo sem seguida foram revolucionadas pelo surgimento da internet e das Tecnologias Digitais da Informação e Comunicação, que ocasionou conectividade, ampliando a oferta dessa modalidade de ensino, através das plataformas digitais. Tanto que uma das afirmações mais comuns hoje em dia, é que o mundo está vivendo um processo de grandes transformações, profundas e aceleradas e que se modificam a cada instante (Bruzzi, 2016).

Bruzzi (2016, p. 479) reitera ainda que não podemos negar que há uma nova demanda para um novo tipo de tecnologia, que, por sua vez, vem sendo gerada em decorrência do processo de maturação tecnológica e do desenvolvimento das telecomunicações.

Nesse sentido, em uma sociedade em que mais 148,4 milhões de pessoas de 10 anos ou mais de idade usam telefone móvel celular para uso pessoal, o acesso às informações se torna cada vez mais veloz. Esse processo de transformação digital em nossa sociedade faz com que agora todos estejam no modo online, onde sentem-se motivados a fazer atividades que antes só seria possível presencialmente (IBGE, 2019).

Nos dias atuais, essa conectividade faz parte da vida de milhões de pessoas.

Com o avanço imposto pela pandemia do COVID-19, uma nova tecnologia surge com as mesmas similaridades da Educação a Distância, mas não igual, a começar pelo propósito que cada uma delas tem como características, porém, com o mesmo objetivo em comum: o uso da tecnologia como meio de acesso ao conhecimento.

Dessa forma, o Ensino Remoto surgiu como protagonista em meio à essa pandemia, trazendo consigo desafios de ressignificar nossas práticas e as metodologias de ensino e aprendizagem, pois, diferentemente da EaD, o Ensino Remoto não disponibiliza de um Ambiente Virtual de Aprendizagem - AVA previamente testado para essa finalidade e sim interações virtuais improvisadas, além de não ter um processo avaliativo padronizado como o que ocorre na $\mathrm{EaD}$, onde mesclam-se a um método híbrido de avaliação, ora provas online com avaliações realizadas em polo presencial, havendo interação com o professor que conduz as aulas e com o tutor, que dá o auxílio e suporte nas atividades no Ambiente Virtual de Aprendizagem.

Ademais, é necessário que fique claro que o ensino remoto não é sinônimo de Educação a Distância, conforme:

Ensinar remotamente não é sinônimo de ensinar a distância, embora esteja diretamente relacionado ao uso de tecnologia e, nesse caso, digital. $\mathrm{O}$ ensino remoto permite o uso de plataformas já disponíveis e abertas para outros fins, que não sejam estritamente os educacionais, assim como a inserção de ferramentas auxiliares e a introdução de práticas inovadoras. A variabilidade dos recursos e das estratégias bem como das práticas é definida a partir da familiaridade e da habilidade do professor em adotar tais recursos. Ensinar remotamente permite o compartilhamento de conteúdos escolares em aulas organizadas por meio de perfis [ambientes controlados por login e senha] criados em plataformas de ensino, como, por exemplo, SIGAA e MOODLE, aplicativos como Hangouts, Meet, Zoom ou redes sociais (Garcia et al. 2020, p.5).

As mudanças abruptas ocorridas com as aulas remotas têm desafiado docentes e discentes, afinal, para que se possa adaptar a essa nova rotina de substituir uma sala de aula presencial para os ambientes virtuais é necessário maior investimento de tempo e em tecnologia.

\section{Metodologia}

Esta pesquisa mista com predominância qualitativa e do tipo exploratória, partiu de um levantamento realizado através das respostas obtidas de 74 discentes de graduação dos cursos de Pedagogia e Educação Física, matriculados no Instituto de Ciências da Educação, da Universidade Federal do Pará.

Tal formato de pesquisa, segundo Sampieri; Collado e Lucio (2013, p. 550), combina "ao menos um componente 
quantitativo e um qualitativo no mesmo estudo ou projeto de pesquisa", de forma sistemática e em função de uma análise mais fidedigna do fenômeno a ser estudado.

O protocolo da pesquisa foi iniciado encaminhando comunicação às diretoras dos cursos solicitando que compartilhassem a chamada para que os/as alunos/as pudessem contribuir com a presente pesquisa, juntamente com o envio do link. O questionário constou de 10 questões, sendo 8 fechadas e duas questões abertas. O envio para o formulário disponível na plataforma Google Forms para os/as respondentes se deu por via whatsapp. Os discentes tiveram em média duas semanas para responder ao questionário.

A adoção do questionário, como instrumento de coleta de dados nesta pesquisa, ocorreu em virtude da popularidade deste tipo de pesquisa e por dar conta de mensurar uma ou mais variáveis presentes no levantamento de dados (Sampieri; Collado $\&$ Lucio, 2013). A diversidade de questões abertas e fechadas permitiu uma amplitude de respostas que foram fundamentais para a compreensão do fenômeno em questão, uma vez que "a escolha do tipo de perguntas para o questionário depende do quanto é possível anteciparmos as possíveis respostas, do tempo que dispomos para codificar e se queremos uma resposta mais precisa ou saber mais sobre alguma questão" (Sampieri; Collado \& Lucio, 2013, p. 240).

Assim, apresentaremos os resultados da pesquisa a partir de tais categorias temáticas. sendo a primeira referente ao curso, turno e período em que se encontram matriculados/as, assim como são as condições materiais de acesso às tecnologias digitais e atividades online e/ou offline e o uso dos equipamentos tecnológicos e a segunda categoria concernente, sobre as questões dissertativas, analisaremos a seguir, de forma aprofundada, os pontos positivos e negativos que emergiram a partir da fala dos sujeitos da pesquisa, apontando os conflitos, a exemplo de ensino e aprendizado, recursos físicos, tecnológicos digitais e de conectividade, a conduta discente e as especificidades da região Norte, fatores estes impostos pelo isolamento social em virtude da pandemia do COVID-19, que tem confrontado professores/as e alunos/as diante da nova realidade, para a qual, não nos houve preparo e nem formação adequada.

Na codificação qualitativa, as categorias são conceitos, experiências, ideias, fatos relevantes e com significado [...] O número de categorias encontradas e criadas depende do volume de dados, da formulação do problema, do tipo de material revisado e da extensão e profundidade da análise [...] A complexidade da categorização também deve ser considerada, uma unidade pode gerar mais de uma categoria ou ser colocada em duas, três ou mais categorias [...] Algumas categorias podem ser tão complexas que é necessário fragmentá-las em várias [...] A categoria fragmentada depois pode passar a ser um tema (Sampieri; Collado \& Lucio, 2013, p. 458-462).

Os/as voluntários/as assinaram o Termo de Consentimento Livre e Esclarecido e ficaram cientes de que a qualquer momento poderiam, sem constrangimento, deixar de participar da pesquisa. Foram tomadas todas as precauções no intuito de preservar a privacidade dos voluntários/as.

Da análise, emergiram algumas unidades de significado elencadas nas Figuras 1 e 2 e discutidas no tópico a seguir: 
Figura 1: pontos positivos no ensino remoto.

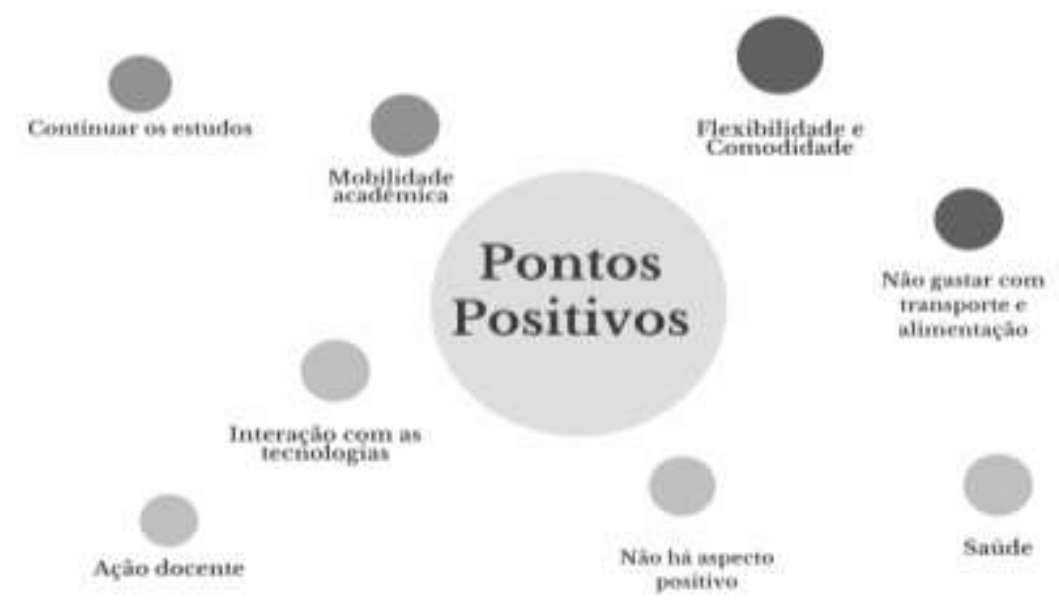

Fonte: Dados da pesquisa (2021).

Figura 2: pontos negativos no ensino remoto.

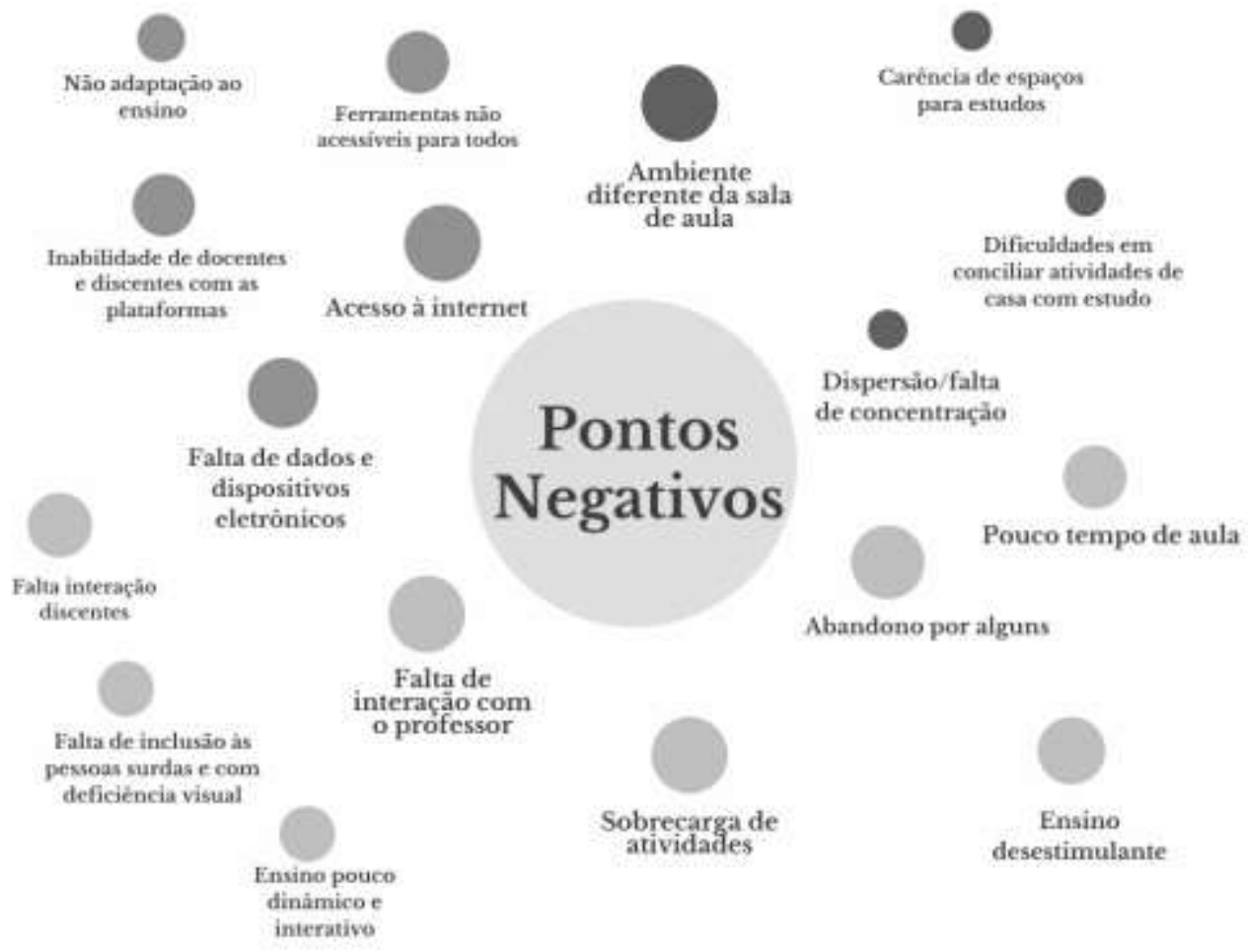

Fonte: Dados da pesquisa (2021).

\section{Resultados e Discussão}

Nessa perspectiva, sob à escuta sensível da voz discente, passamos a analisar o acesso dos/as discentes dos cursos de Pedagogia e Educação Física, do Instituto de Ciências da Educação, da Universidade Federal do Pará, às tecnologias digitais e suas representações quanto às dificuldades e potencialidades do ensino remoto, nesse atual momento que estamos vivenciando a pandemia do COVID-19.

Em tese, descreveremos os resultados obtidos da pesquisa a partir das categorias, sendo a primeira referente ao curso, turno e período em que se encontram matriculados, assim como a) condições materiais de acesso às tecnologias digitais, uso dos 
equipamentos tecnológicos e atividades online e offline; b) opinião dos estudantes sobre a Educação Remota no período de isolamento social e c) conflitos subjacentes ao Ensino Remoto durante a pandemia.

Observou-se que 74 foram os/as estudantes respondentes, sendo que 68,1\% são do turno matutino, $18,1 \%$ matriculados/as no turno da tarde e 13,9\% do noturno. Em maioria, 67,6\% são alunos/as do curso de Pedagogia e 32,4\% oriundos/as do curso de Educação Física; quanto ao período em que se encontram matriculados, 29,7\% são calouros/as do primeiro período; 9,5\% declaram-se do segundo período; 5,4\% do terceiro período; 9,5\% referem-se ao quinto período; $14,9 \%$ ao sexto período; $20,3 \%$ são discentes do sétimo período; $4,1 \%$ do oitavo e $6,8 \%$ declaram-se alunos/as fora de bloco. Não obtivemos resposta dos alunos matriculados no quarto período.

Em uma análise preliminar é possível inferirmos alguns aspectos que reverberam na ausência de participação dos/as alunos/as nesta pesquisa, visto que, conforme os dados obtidos pelas direções das Faculdades de Educação e Educação Física, os discentes ativos e matriculados nesse período letivo 2021.1, correspondem a 727 discentes do curso de Pedagogia e 162 no curso de Educação Física. Notadamente há um número quase dez vezes maior que o $n=74$ desta pesquisa, embora saibamos que nem todos estão matriculados/as insta evidenciar que mesmo sendo uma pesquisa com aval das direções, os/as alunos/as se mostraram reticentes quanto a mais uma atividade a ser realizada e outros/às sequer tiveram condições de receber a mensagem por falta de conexão de dados, um nó que atravanca a comunicação de alunos/as com a universidade.

Quanto às condições dos discentes ao acesso às tecnologias digitais e, consequentemente, à garantia de participar das aulas e atividades de ensino remoto, constatou-se que $89,2 \%$ utilizam o aparelho celular ou smartphone para acessar essas aulas; $35,1 \%$ usam o notebook; $6,8 \%$ o PC e 2,7\% usam o tablet; e que citam os tipos de internet mais usados por eles, destacando-se assim: 75,7\% usam Wi-fi; $41,9 \%$ utilizam dados móveis e 1,4\% acessam através da internet cabeada.

Diante da questão sobre o Programa de Inclusão Digital, oferecido aos/às discentes em condições de vulnerabilidade socioeconômica e que tem como objetivo permitir o acesso a equipamentos e tecnologias para as atividades acadêmicas do ensino remoto, verificou-se que 60,8\% dos/as respondentes não se inscreveram no Programa e 39,2\% solicitaram o respectivo auxílio e deste apenas 21,6\% foram contemplados com os benefícios e 78,4\% admitem não terem sidos agraciados/as.

Ainda sobre o Programa de Inclusão, foi questionado aos/às contemplados/as com os benefícios, quais recursos receberam, no que obtivemos a seguinte resposta: $88,2 \%$ receberam o auxílio chip; $11,8 \%$ afirmam ter sido contemplado com notebook e nenhum respondente citou o auxílio tablet.

Essas questões relatadas nos propiciam uma breve reflexão acerca das dificuldades dos discentes, sobretudo, quanto ao acesso a equipamentos tecnológicos e das condições materiais mínimas para seu desenvolvimento acadêmico nos cursos de graduação, principalmente, neste contexto histórico, em que as exigências pelo ensino remoto se fazem sentir com muita veemência. Cabe o questionamento sobre a eficácia do ensino remoto com um público com este grau de dificuldades e condições materiais insuficientes de acesso às tecnologias digitais.

Após as primeiras leituras sobre os dados coletados, verificou-se que a maioria dos/as respondentes referiram-se ao Ensino Remoto, como uma possibilidade de prosseguir os estudos, citam "O ERE proposto na UFPA em 2020 permitiu a flexibilização dos horários de aula tornando possível adaptá-las às novas formas de organização das tarefas diárias e trabalho contexto da COVID-19", além de "para quem reúne condições de participar desse processo excludente, o ERE se torna uma solução para amenizar a lacuna da formação acadêmica ocasionada pela paralisação das aulas presenciais", destacando-se também a possibilidade de ter "horários mais flexíveis e a comodidade de poder estudar em casa", além de possibilitar "a participação em eventos, aulas, palestras, dentre outras, que antes nem imaginava participar na minha própria universidade, bem como em outras".

Porém, ainda que tenham se declarado favoráveis à educação remota, enfatizaram algumas dificuldades, como: "é totalmente desmotivador comparado com o presencial"; levando em consideração "a dificuldade de aprender em um ambiente 
diferente da sala de aula sempre tem algo pra nos distrair e não nos concentramos 100\% e fora que temos nossas dificuldades de compreensão", reiterando que "além disso temos a questão de estar em casa sendo mais que alunos, pois em casa somos também esposa, mãe, dona de casa. E quando as pessoas nos veem em casa não conseguem separar que em um momento somos estudantes, além de termos que nos virar financeiramente também".

Sobre o Ensino Remoto, Almeida et al. (2020) asseguram que educação remota não é a solução para os problemas acarretados à educação pela pandemia, mas uma política de redução de danos e tem que ser considerada e realizada, sendo apenas uma alternativa de continuidade à formação acadêmica adotada pelas instituições de ensino.

Os dados indicam algumas posições dos/as alunos/as ante a utilização dessa modalidade de ensino, tais como: mudanças nos padrões das aulas, falta de concentração e ausência de espaços apropriados para estudos, além da falta do contato humano. Abaixo, encontramos mais argumentos quanto à sua rejeição, como por exemplo:

(...) o fato de não estar em um ambiente apropriado para aulas me faz ficar disperso durante a mesma.

(...) não conseguir separar os estudos dos problemas da casa por não ter lugar adequado para estudar.

(...) uma aula sem cheiro dos participantes do processo de ensino aprendizagem.

(...)a falta do contato pessoal físico, visto que é muito mais fácil resolver dúvidas ao vivo, além da exposição alta ao celular.

Outrossim, os/as que analisam os pontos positivos da Educação Remota preocupam-se com o andamento das atividades acadêmicas do curso, o processo de ensino e de aprendizagem e os atrasos inevitáveis, caso não se encontrem outras maneiras de retorno presencial:

(...) possibilita a continuidade do curso, apesar da pandemia em que nos encontramos.

(...) conseguimos assistir às aulas de qualquer lugar.

(...) possibilidades de aprender não só os métodos que a faculdade impõe, mas, também novos métodos tecnológicos.

(...) esse ano estamos avançando no semestre, não estamos ficando para trás em relação a outras universidades da capital.

O ensino remoto mediado por tecnologia digital, nesta situação de pandemia, é um arranjo circunstancial de emergência, longe de atender as demandas de uma proposta educacional que garanta o acesso, permanência e possibilidades satisfatórias de aprendizagem (Cunha et al., 2020)

Outra problemática que foi relatada diz respeito aos recursos físicos, tecnológicos digitais e conectividade, onde fazem as seguintes referências: "que o principal ponto negativo do Ensino Remoto é a falta de internet de qualidade a todos os envolvidos (alunos/as e professores/as)" e "o computador/notebook que nem todos os alunos têm e é preciso para produzir trabalhos" e as "limitações através do uso do celular". Quanto à conectividade, avaliam que "somos refém do sinal de internet, nossa cidade possui muita interferência climática no que diz respeito às chuvas e isso atrapalha bastante a nossa permanência nas salas virtuais". A desigualdade no acesso às atividades online por parte dos alunos/as traz à tona "principalmente a precarização do ensino em virtude da complexidade que é conectar pessoas das mais diversas realidades sociais em salas virtuais".

Para outros, esses fatores anteriormente citados apresentam a vantagem em se ter "uma maior interação com a tecnologia", com o uso de "novas dinâmicas de ensino" e "tecnologias alternativas, mesmo que de forma forçada, em breve proporcionará novas possibilidades para quem está incluso nas aulas, grupos de pesquisa e etc.", gerando "a possibilidade de novas experiências, domínio de ferramentas digitais, utilização de recursos tecnológicos, mais metodologias ativas".

Enfatizaram ainda sobre as problematizações relacionadas às dificuldades na aprendizagem, a falta de domínio tanto por discentes quanto docentes, e, também a relação professor-aluno, tais como: o excesso de atividades enviados pelos professores, fazendo com que "isso deixa os alunos esgotados" além de "uma grande quantidade de trabalhos complexos e 
discussões" e "a aparente inabilidade dos discentes e docentes com as plataformas de reunião virtual". Do outro ponto de vista, observou-se que "o acolhimento dos professores tem sido muito importante", havendo "maior preocupação com o aprendizado do aluno" e alguns gravam as aulas, e as ferramentas tecnológicas auxiliam muito, inclusive "tem professores que utilizam até mesmo jogos", tornando as aulas mais objetivas e de qualidade.

Ainda nesse processo, verifica-se que a figura do professor, como mediador, torna-se de suma importância para criar as condições necessárias para o ensino- aprendizagem. Assim, dentro da sensibilidade de ouvir a opinião dos/as alunos/as sobre o ensino remoto no contexto atual de pandemia, observou-se as manifestações que remetem para uma mediação entre as dificuldades com manuseio das plataformas digitais e a possibilidade de criar alternativas. Destacando-se essas colocações nas seguintes proposições:

(...) professores incapacitados para tal modalidade.

(...) falta de flexibilidade por parte de alguns professores.

(...) não são todos, mas alguns professores se sensibilizaram e acabaram permitindo gravações de aula para que em momentos posteriores a aula síncronas pudéssemos rever.

(...) dependendo do professor, as ferramentas tecnológicas auxiliam muito e tornam tudo mais lúdico e visual.

Nesse contexto, Alves et al. (2020) pondera sobre a importância do papel do professor nesse período de pandemia de (re)inventar a profissão docente em tempos de adversidade, o que não é fácil, (re)inventar a nós mesmos e nossos modos de vida em situação de distanciamento social, o que também não é nada fácil, mas sim, é possível".

Essa postura perceptível e de acolhimento às dificuldades enfrentadas pelos/as alunos/as no âmbito do trabalho remoto e da ressignificação de sua práxis na educação remota vai além do ensino remoto que estamos vivenciando, passa a ser uma importante reflexão acerca da didática.

Dentre outras perspectivas, os/as respondentes enfatizaram que o Ensino Remoto oferece vantagens, como "ficar em casa e não se contaminar" e "tem uma economia de tempo e dinheiro (transporte/alimentação)", pois alguns alunos/as argumentam morar distante do Campus, às vezes tendo de sair de casa com duas horas de antecedência, assim como "possibilita a continuidade do curso apesar da pandemia em que nos encontramos".

Sobre o Programa de Inclusão Digital oferecido pela Universidade Federal do Pará, como auxílio para que discentes em vulnerabilidade socioeconômica pudesse participar das atividades online, pode-se observar mediante às falas discentes que:

(...) o ER requer acesso à rede de dados e dispositivos eletrônicos que por vezes não estão acessíveis ao público em geral, ocasionando o abandono das aulas por alguns alunos ou concorrência em editais de assistência estudantil, de forma que nem toda a demanda será atendida.

(...) A falta de internet pois quando fui me inscrever surgiram uma série de coisas bem complicadas que dificultaram muitos estudantes que precisam muito.

(...) apesar do esforço da UFPA para disponibilizar insumos para a realização do ERE, as ferramentas não estão acessíveis a todos.

(...) internet lenta do chip.

(...) a dificuldade é a Internet, agora usando o chip da Universidade cai muito a Internet.

(...) avanço em inclusão digital no Instituto.

(...) falta de Inclusão digital a alunos em vulnerabilidade social, residentes de interiores com acesso remoto à internet.

Sobre a necessidade de se repensar a acessibilidade à internet e suas condições para prosseguimento das atividades acadêmicas, Santos Junior e Monteiro (2020) dizem que todo esse processo de integração das tecnologias digitais precisa garantir a participação de todos, de forma igualitária, para não gerar exclusão educacional.

(...) falta de Inclusão a alunos com deficiência auditiva e/ou visual.

(...) Inclusão de pessoas com necessidades especiais. 
O Ensino Remoto evidencia também a fragilidade e falha de inclusão na educação aos/às discentes surdos/as e com deficiência visual, preconizados na Declaração Internacional de Montreal sobre Inclusão (2001) como o direito de toda pessoa à educação, independentemente de sua condição.

\section{Considerações Finais}

A pandemia imposta pelo COVID-19 nos coloca defronte a uma nova realidade de ensino, em meio à crise sanitária instaurada, as instituições educacionais foram obrigadas a alterar radicalmente tanto as rotinas, quanto às práticas educativas de formação acadêmica. Medidas nem um pouco ideais necessitam ser tomadas a fim de dar continuidade aos cursos de graduação, assim juntos, estamos enfrentamos essa transição do ensino presencial para o ensino remoto, onde se tem permitido a docentes e discentes experienciar novos contextos no processo de comunicação em termos educacionais. Da noite para o dia, fomos jogados no virtual, podendo participar de uma aula através de um aparelho celular em meio a um engarrafamento no trânsito ou de um cômodo qualquer de nossa casa sala.

O ensino remoto nos permite essa flexibilidade, mas também nos faz perder a concentração quando deveríamos estar atentos. Essa adaptação a esta nova realidade não é um processo fácil nem a mais adequada, ainda reflete a exclusão de indivíduos que não são abrangidos pelas tecnologias e nem tem acesso à internet, além dos cidadãos que apresentam necessidades especiais, como pessoas surdas e com deficiência visual.

Fica evidente que o uso das tecnologias na educação remota tem assumido um importante papel na mediação do ensinoaprendizagem, mas que as mesmas não podem substituir o professor na formação total do/a aluno/a, e principalmente no processo avaliativo.

Embora não seja o objetivo desta pesquisa, deixamos evidenciado que o lar pode ser um espaço propício e inadequado às atividades educacionais quando se tem o olhar direcionado às demandas relacionadas ao gênero, ou seja, ainda é possível verificarmos a predominância da execução das atividades do lar relegada às mulheres independentemente da faixa etária, se estudantes residentes nas casas de seus responsáveis, seja como as responsáveis pelo próprio lar, o cenário assemelha se no que tange às obrigações domésticas. Por outro lado, os alunos destacam a comodidade do estudo no lar sem evidenciar qualquer demanda que atrapalhasse os seus estudos.

Como sugestão para futuros trabalhos, por evidenciar relevância favoráveis, podemos salientar o papel do professor e o uso das TDICs, como ferramenta de interação na relação professor-aluno e desenvolver estudos sobre a acessibilidade e inclusão das pessoas com deficiência visual e surdas na Educação Remota.

\section{Referências}

Almeida, F. J. d., Almeida, M. E. B. d., \& Silva, M. d. G. M. d. (2020). De Wuhan a Perdizes: Trajetos educativos. EDUC.

Alves, L. (2020). Educação Remota: entre a ilusão e a realidade. Interfaces Científicas - Educação, 8(3), 348-365. https://doi.org/10.17564/23163828.2020v8n3p348-365

Alves, L. d. L., Bornat, M. A., \& Martins, M. C. F. (2020). Do Ensino presencial para o remoto: os novos desafios dos professores e das instituições de ensino superior. Plataforma Espaço Digital. https://editorarealize.com.br/artigo/visualizar/68351

Brasil (1996). Lei n. 9.394, de 20 de dezembro de 1996. Estabelece as diretrizes e bases da educação nacional. Presidência da República. http://www.planalto.gov.br/ccivil_03/LEIS/L9394.htm.

Brasil (2014). Lei 12965. (2014, 23 de abril). Estabelece princípios, garantias, direitos e deveres para o uso da Internet no Brasil. Presidência da República. http://www.planalto.gov.br/ccivil_03/_ato2011-2014/2014/lei/112965.htm

Brasil (1988). Constituição da República Federativa do Brasil de 1988 http://www.planalto.gov.br/ccivil_03/Constituicao/constitui\%C3\%A7ao.htm

Brasil (2019). Instituto Brasileiro de Geografia e Estatística| Biblioteca. https://biblioteca.ibge.gov.br/visualizacao/livros/liv101705_informativo.pdf

Brasil (2020). Portaria no 188, de 3 de fevereiro de 2020. — Declara Emergência em Saúde Pública de importância Nacional (ESPIN) em decorrência da Infecção Humana pelo novo Coronavírus (2019-nCoV). http://www.in.gov.br/en/web/dou/-/portaria-n-188-de-3-de-fevereiro-de-2020-241408388. 
Bruzzi, D. G. (2016). Uso da tecnologia na educação, da história à realidade atual. Revista Polyphonía, 27(1), 475-483. https://doi.org/10.5216/rp.v27i1.42325

Conceição, W. L. d., Corsino, L. N., \& Costa, S. C. (2021.). A pandemia na e da socioeducação: nem "socio" tampouco “educação. Áskesis, 10 (no prelo) (1).

Costa, W. C. P., \& Conceição, W. L. da. (2021a). School Physical Education in the pandemic context in the Municipality of Vigia de Nazaré in the state of Pará. Research, Society and Development, 10(10), e105101018728. https://doi.org/10.33448/rsd-v10i10.18728

Costa, W. C. P., \& Conceição, W. L. da. (2021b). Educação física escolar e educação de jovens e adultos: desafios da docência no ensino remoto emergencial. Caderno De Educação Física E Esporte, 19(3), 1-6. https://doi.org/10.36453/cefe.2021.n3.27629.

Cunha, L. F. F. d., Silva, A. d. S., \& Silva, A. P. d. (2020). O ensino remoto no Brasil em tempos de pandemia: diálogos acerca da qualidade e do direito e acesso à educação | Revista Com Censo: Estudos Educacionais do Distrito Federal. http://www.periodicos.se.df.gov.br/index.php/comcenso/article/view/924

Declaração Internacional de Montreal sobre Inclusão. (2001.). AMPID - Associação Nacional dos Membros do Ministério Público de Defesa dos Direitos das Pessoas com Deficiência e Idoso. http://www.ampid.org.br/ampid/Docs_PD/Convencoes_ONU_PD.php\#declamontreal

Diretrizes Curriculares Nacionais Gerais da Educação Básica. (2013). Ministério da Educação -http://portal.mec.gov.br/index.php?option=com_docman\&amp; view=download\&amp;alias=13448-diretrizes-curiculares-nacionais-2013-pdf\&amp;Itemid=30192

Franco, M. A. d. R. S. (2016). Prática pedagógica e docência: um olhar a partir da epistemologia do conceito. SciELO - Brasil. http://www.scielo.br/scielo.php

Garcia, T. C. M., Morais, I. R. D., Zaros, L. G., \& Rêgo, M. C. F. D. (2020). Universidade Federal do Rio Grande do Norte: Ensino remoto emergencial: proposta de design para organização de aulas. Universidade Federal do Rio Grande do Norte: Home. https://repositorio.ufrn.br/ handle/1234567 89/29767?script=sci_arttext\&amp;pid=S2176-66812016000300534\&amp;lng=pt\&amp;nrm=iso

Oliveira, S. da S., Silva, O. S. F., \& Silva, M. J. de O. (2020). Educar na incerteza e na urgência: implicações do ensino remoto ao fazer docente e a reinvenção da sala de aula. educação, 10(1), 25-40. https://doi.org/10.17564/2316-3828.2020v10n1p25-40

Paho.org. 2021. Folha informativa sobre COVID-19 - OPAS / OMS | Organização Pan-Americana da Saúde. <https://www.paho.org/pt/covid19>

Parecer CNE/CP No: 5 (2020,28 de abril) Reorganização do Calendário Escolar e da possibilidade de cômputo de atividades não presenciais para fins de cumprimento da carga horária mínima anual, em razão da Pandemia da COVID-19. http://portal.mec.gov.br/index.php?option=com_docman \&amp;view=download\&amp;alias $=1450$

Universidade Federal do Pará. (2020). Resolução CONSEPE № 5.294/2020. Aprova, de forma excepcional e temporária, o Ensino Remoto Emergencial em diferentes níveis de ensino para os cursos ofertados pela Universidade Federal do Pará, em decorrência da situação de pandemia do novo Coronavírus -COVID19, e dá outras providências http://proeg.ufpa.br/images/Artigos/Normas/Resolucao_5294_2020_CONSEPEAprovaoEREnaUFPA.pdf

Sampieri, R. H., Collado, C. F., Lucio, M. del P. B. (2013). Metodologia de Pesquisa. Editora Penso.

Santos Junior, V. B. dos, \& Monteiro, J. C. da S. (2020). Educação e COVID-19: as tecnologias digitais mediando a aprendizagem em tempos de pandemia. Revista Encantar - Educação, Cultura E Sociedade, 2, 01-15. e https://www.revistas.uneb.br/index.php/encantar/article/view/8583

Senhoras, E. M. (2020). Coronavírus e educação: análise dos impactos assimétricos | Senhoras | Boletim de Conjuntura (BOCA). Portal de Revistas da UFRR. https://revista.ufrr.br/boca/article/view/Covid-19Educacao/2945

Silva, A. J. F. d., Silva, C. C. d., Tinôco, R. d. G., Araújo, A. C. d., Venâncio, L., Neto, L. S., Freire, E. d. S., \& Conceição, W. L. d. (2021). Dilemmas, Challenges and Strategies of Physical Education Teachers-Researchers to Combat COVID-19 (SARS-CoV-2) in Brazil. Frontiers. https://www.frontiersin.org/articles/10.3389/feduc.2021.583952/full

Silva, A. V. B. D. (2020). Coronavírus: A entropia do século XXI. ResearchGate. https://www.researchgate.net/publication/343558333_Co ronavirus_A_entropia_do_seculo_XXI

Souza, L. K de. (2019). Pesquisa com análise qualitativa de dados: conhecendo a Análise Temática. Arquivos Brasileiros de Psicologia, 71(2), 51-67. https://dx.doi.org/10.36482/1809-5267.ARBP2019v71i2p.51-67

Stringhini, M. L. F., Menezes, I. H. C. F., Priebe, D. D. A. M., Cavalcante, R. B. M., Freitas, A. T. V. de S., Guimarães, M. M., Souza, T. A. C., Ferreira, T. A. P. de C., Martins, K. A., \& Mortoza, A. S. (2021). Ensino Remoto Emergencial: Implantação e resultados na percepção de estudantes universitários. Research, Society and Development, 10(9), e11610917744. https://doi.org/10.33448/rsd-v10i9.17744 